\title{
Guerra, movilización y resistencia Realista en el Sur Andino. Arequipa, 1820-1821: Visión preliminar
}

Helbert Jonathan Suyo Naupa

Pontificia Universidad Católica del Perú

Recibido: 16-03-21

Aprobado: 29-06-21

doi: 10.46476/ra.v2i1.101

\section{Resumen}

El presente artículo analiza el impacto de una serie de eventos independentistas en el virreinato peruano y la intendencia de Arequipa durante 1820 y 1821. Proponemos que Arequipa se constituyó en un centro de resistencia realista hasta el final de las guerras por la independencia, transformándose en uno de los últimos lugares de resistencia del virreinato peruano. Diversos factores permiten explicar esta situación: el relativo éxito de las reformas borbónicas, la experiencia previa enfrentando a los enemigos del rey y el posicionamiento de criollos arequipeños en puestos claves de gobierno. Metodológicamente, el artículo se sustenta en la revisión de literatura especializada y fuentes primarias de archivos de Arequipa, así como fuente primaria impresa, escasamente analizadas por la historiografía nacional.

Palabras clave: Arequipa, Guerras de Independencia, reformas borbónicas, Sur Andino. 


\section{Summary}

This article analyzes the impact of a series of independence events in the Peruvian viceroyalty and the Intendance of Arequipa during 1820 and 1821. We propose that Arequipa became a center of realistic resistance until the end of the wars of independence, being one of the last places of resistance of the Peruvian viceroyalty. Several factors explain this situation: The relative success of the Bourbon reforms, previous experience facing the King's enemies, and the positioning of Arequipa Creoles in key government positions. Methodologically, the article is based on a review of specialized literature and primary sources from various archives of Arequipa and printed primary source, scarcely analyzed by national historiography.

Keywords: Arequipa, Wars of Independence, Bourbon reforms, South Andean.

\section{Resumo}

O presente artigo analisa o impacto de uma série de eventos pró-independência no vice-reinado peruano e a intendência de Arequipa durante os anos 1820 e 1821. Propomos que Arequipa se tenha tornado um centro de resistência realista até ao fim das guerras pela independência, tornando-se um dos últimos lugares de resistência no vice-reinado peruano. Esta situação pode ser explicada por uma série de fatores: $\mathrm{O}$ relativo sucesso das reformas Bourbon, a experiência anterior de confrontar os inimigos do rei e o posicionamento dos Creoles de Arequipa em postos-chave do governo. Metodologicamente, o artigo baseia-se numa revisão da literatura especializada e de fontes primárias dos arquivos de Arequipa e de fontes primárias impressas, que foram pouco analisadas pela historiografia nacional.

Palavras-chave: Arequipa, Guerras de Independência, Reformas Bourbon, Sul Andino. 


\section{Introducción}

El objetivo del presente artículo es analizar el contexto político, militar y religioso de la intendencia de Arequipa durante 1820 y 1821. Estos años fueron marcados por la incursión marítima patriota al virreinato peruano, lo que conllevó a la desocupación de Lima por parte de las fuerzas leales al rey. Posteriormente, dichas fuerzas, al mando del virrey José de la Serna e Hinojosa (1821-1824), se trasladaron a Cuzco, ciudad que se convirtió en la nueva capital del virreinato hasta el final de la guerra de la independencia.

Durante la invasión y ocupación patriota de Lima en 1821, los puertos intermedios también fueron objetivo de movimientos patriotas. En más de una ocasión, estas fuerzas desembarcaron y avanzaron a través de las subdelegaciones de Arica, Tacna, Moquegua, Tarapacá y Arequipa. Entonces, ¿Cuál fue la situación de la intendencia de Arequipa durante las incursiones patriotas en los puertos intermedios?, ¿Qué acciones tomaron las autoridades arequipeñas ante este nuevo vacío de poder? y ¿Cuál fue la respuesta de los pobladores arequipeños durante esta nueva coyuntura?

Algunos estudios señalan que, durante el proceso de guerras de la independencia, la intendencia de Arequipa y sus habitantes brindaron apoyo sostenido a la causa del rey (Riveros, 2017). También se ha sostenido que Arequipa solo brindó apoyo a la revolución del Cuzco de 1814-1815 (Zegarra, 1973). Y que fue un bastión realista hasta el final de la guerra (Chambers, 2003). ${ }^{1}$ Lo cierto es que, Arequipa ganó notoriedad debido a su posición geográfica y su extensa franja costera que iba desde de Ica (Lima) y el de Atacama (Potosí). Esta característica permitió tener acceso a las provincias de arriba, hizo posible una rápida movilización de tropas y permitió el intercambio fluido de información.

Sin embargo, su posición en el espacio sur andino la hizo proclive a la filtración de emisarios y escritos subversivos, durante los primeros años de conflicto, situación que prosiguió y se mantuvo vigente hasta el final de la guerra de la independencia. ${ }^{2}$ De esta forma, comprobamos que en Arequipa hubo apoyo a la causa patriota. Lo que nos demuestra lo complejo de las guerras de la independencia; si bien el apoyo

1. La opinión de Kendall Brown, difiere. Dice, en la secuela de la rebelión de 1780, los arequipeños reprimieron su malestar. Al menos la región se convirtió superficialmente en un bastión realista. (Brown, 2008, p. 272.)

2. Juan Agustín Lira refiere que para 1820-1821, tenía conocimiento de los acontecimientos en Tacna, sus contactos patriotas le manifestaron que una división patriota desembarcaría en el puerto de Quilca siempre y cuando se les auxilie y obrasen a su favor. Indica, que un grupo de ciudadanos se reunieron en la hacienda del señor [Domingo] Tristán. Entre ellos figuraban Mariano Santos Quiroz y su hermano Anselmo entre otros. En dicho lugar se decidió que él sería uno de los corresponsales del señor almirante [Cochrane]. Junto con Anselmo Quiroz y Manuel Mayo debían marchar a Quilca, para realizar un plan de operaciones, recibir las instrucciones y obrar en favor de la patria en los pueblos cercanos. CDIP, Tomo XXVI, volumen 3, 1972, pp.8-9. 
patriota fue minoritario, a todas luces fue notorio y de público conocimiento. (Wibel, 1975, pp. 232-268; Suyo, 2020).

Siguiendo la idea propuesta, Arequipa, Huancavelica, Huamanga, Cuzco, Puno y las intendencias altoperuanas, durante 1821 a 1825, no fueron un bastión realista como se ha sostenido, sino espacios de resistencia y uno de los últimos reductos de las fuerzas leales al rey. Cada una de estas unidades políticas tuvo características propias que se fueron modificando a medida que el conflicto avanzaba en sus respectivos espacios. Particularmente, Arequipa incrementó su importancia militar porque la región se convirtió en la llave de la defensa del sur del Perú. (Wibel, 1975).

El enfrentamiento de los denominados patriotas y servidores leales al rey en cada intendencia sur andina merece una investigación aparte, así como la identificación de actores y sus conexiones independentistas dentro y fuera de este espacio. Las investigaciones de Lanas (2016, 2017, 2018), Aguilar (2013), Glave (2015, 2020), Valcárcel (2018) y Suyo (2020) han demostrado la dinámica, tensión y confrontación de estos actores contra las fuerzas realistas. También se ha comprobado que los levantamientos en dichos espacios no fueron eventos aislados, sino que respondieron a una coordinación anterior o fueron la respuesta de conexiones previamente establecidas.

Se pretende estudiar dos aspectos: el primero, describir las características de la intendencia de Arequipa durante los años de 1820 y 1821, y el segundo, analizar el espacio arequipeño como uno de los últimos soportes del imperio español en Hispanoamérica. La revisión de manuscritos en el Archivo Arzobispal de Arequipa (AAA), Archivo Regional de Arequipa (ARA), Archivo Municipal de Arequipa (AMA) nos permitió reconstruir el escenario y ubicar a sus diferentes actores. El artículo se estructura en cuatro partes; en la primera, hablamos sobre la reformulación del espacio virreinal peruano; en la segunda, desarrollamos la situación de las intendencias sur andinas; en el tercer punto, explicamos la posición de Arequipa en este contexto y la última parte es sobre la incursión patriota a los puertos intermedios.

\section{Reformulación del espacio virreinal peruano: nuevos frentes de batalla}

Los conflictos bélicos que se desarrollaron en el Alto y Bajo Perú de 1809 a 1815, se caracterizaron por una serie de movimientos patriotas y realistas para controlar el territorio correspondiente a la Audiencia de Charcas. La principal característica del ejército peruano fue la presencia hegemónica de criollos en el ejército hasta 1813 (Malamud, 1982; Suyo, 2020). 
Si bien es cierto, esta primera etapa concluyó con éxito a favor de los peruanos, debido a su campaña militar, la situación del virreinato peruano era precaria. ${ }^{3}$ Producto de la penetración insurgente, mediante emisarios y comunicación escrita con las intendencias sur andinas, se realizaron movimientos rebeldes en el bajo Perú. Estos emisarios y escritos burlaron los controles impuestos por las autoridades, y la difusión de ideas tuvo un gran alcance geográfico, llegando a Cerro de Pasco y Trujillo (Davio, 2019; Soux, 2010, pp.71-72).

En 1816, se produjo un cambio de mando importante, el virrey José Fernando de Abascal y Sousa (1806-1816) fue reemplazado por Joaquín de la Pezuela (18161821). Según el historiador Timothy Anna, el gobierno de Pezuela fue destruido por el colapso financiero del régimen y la estrategia de José de San Martín (2003, p. 179). El mismo historiador señala que la caída del Perú comenzó con la caída de Chile en 1817. Por lo que, las costas del Perú estarían abiertas a los corsarios y bloqueos, mientras que Chile podría comerciar por su cuenta con naves extranjeras y comprar los bienes necesarios para hacer la guerra al Perú (Anna, 2003, p.182). No quedaban alternativas se debía reconquistar Chile.

Los realistas peruanos organizaron una expedición que zarpó rumbo a Chile el 9 de diciembre de 1817 y desembarcó el 10 de enero. Posteriormente, el 19 de marzo el ejército de Mariano Osorio logró infligir una derrota al ejército de San Martín en Cancha Rayada. Sin embargo, esta victoria no fue aprovechada por los realistas y dio tiempo a las fuerzas independentistas de reagruparse y aumentar sus efectivos. Finalmente, el 5 de abril de 1818 la contienda se inclinó a favor de los independentistas (Alvarado, 2018, pp. 258-260).

El panorama no era el mejor para las fuerzas peruanas debido a una serie de disputas internas que debilitaron la autoridad del virrey Pezuela. Situación insostenible que provocó un cambio de mando en el teniente general José de la Serna, el 29 de enero de 1821. Esto ha sido interpretado como la remoción de un virrey absolutista, para dar paso a un virrey de tendencia liberal. Fue un contexto aprovechado por San Martín para desembarcar en las costas peruanas. (O’Phelan, 2013, pp. 196-197)

El virrey La Serna permaneció en Lima hasta el 5 de julio de 1821, luego se dirigió a Huancayo. Al conocer esto, la Audiencia del Cuzco le remitió una comunicación oficial, el 5 de noviembre, invitándolo a que se estableciera en el Cuzco. Finalmente, el virrey aceptó el ofrecimiento el 12 de noviembre y llegó a Cuzco el sábado 29 de diciembre de 1821. (O’Phelan, 2013, pp. 197-198). Al parecer, San Martín pensó que tomando Lima caería el Perú, pero los regionalismos peruanos eran fuertes y gozaban de representatividad e identidad propia. Además, su presencia había

3. Anna, 2003, pp.23-52, y pp.150-178; Buller, 84-91; Condori, 2010, p.54; Klein, 1994, pp.36-39. 
quedado reforzada con el sistema de intendencias, impuesto por los Borbones, que daba un margen de autonomía a Arequipa, Cuzco, Huamanga, Tarma, Trujillo. (O'Phelan, 2009, p.121).

La desocupación de Lima reconfiguró política y geográficamente al virreinato peruano. El peso económico y sostenimiento del ejército realista se encontraban en manos de las intendencias sur andinas y altoperuanas. Las constantes cargas económicas y la política inclinada hacia la guerra empeoraron la situación debido al desgaste económico arrastrado desde el inicio del conflicto (Mazzeo, 2000, pp.16-20; Pilco, 2017, pp.47-51 y pp.65-76; Walker, 1999, pp.41-150). Situación que se agravó con la caída de Lima, por lo que:

Arequipa's volumen of imports expanded dramatically after the expulsion of royalist forces from Chile in 1818 and the royalist evacuation of Lima in July 1821. At this point Arequipa became the most critical link between Spain and the last royalist armies in South America which had retreated to the sierra of Perú and Alto Perú. (Wibel, 1975, pp. 274-275). ${ }^{4}$

Los sucesos de Lima hicieron que La Serna abandonase la ciudad (no así el Callao) y se recluyera en el Cuzco, convirtiéndose Arequipa en la plaza principal de abastecimiento, a través de su puerto (Mollendo). (Mazzeo, 2000, p. 43). Es por ello que, la ciudad del Misti experimentó un movimiento de mercaderes procedentes de Lima, pero quien monopolizó el comercio fue Lucas de la Cotera. (Condori, 2011; Wibel, 1975, pp. 269-284).

\section{Las intendencias sur andinas frente a la desocupación de Lima}

Las intendencias sur andinas peruanas y altoperuanas fueron el espacio más grande en Hispanoamérica en sucumbir a las armas patriotas. Fueron un centro de resistencia donde se concentraron los ejércitos leales al rey. La intendencia del Cuzco se convirtió en el nuevo centro político, mientras que Arequipa fue designada como el principal centro religioso. Por esto, se puede observar que el virrey $\mathrm{La}$ Serna no huyó de Lima, simplemente desplazó el epicentro del virreinato al Cuzco, ciudad que en abril de 1823 pidió formalmente a España que se le declarará como capital del Perú. (O’Phelan, 2013, p. 200).

Esto había sido previamente estipulado en la entrevista de Punchauca, evento sumamente relevante. Pues constituyó el primer encuentro de carácter diplomático

4. La intendencia de Arequipa tomó como modelo o base geográfica al obispado del mismo nombre. Esta jurisdicción estuvo conformada por los partidos o subdelegaciones del cercado de Arequipa, Arica, Camaná, Caylloma, Condesuyos, Moquegua y Tarapacá. El sistema de intendencias fue impuesto en el virreinato peruano como parte de las reformas borbónicas y tuvo una vigencia de 41 años que van desde 1784 a 1825. 
entre Perú y España, allí también se reafirmó la idea de traer al Perú un príncipe europeo, y:

[...] producto de estas conversaciones se divide, se fractura el Perú asignándose la región norte a los patriotas y el centro-sur a los peninsulares. Ya en estos momentos se está desestructurando la unidad física y geográfica del territorio, que desembocará en que el Perú, durante la independencia, tenga dos capitales: Lima, la capital patriota, y el Cusco, epicentro del virreinato peruano, desde donde gobernaba el virrey. (O'Phelan, 2019, p. 407).

En ese sentido, resulta pertinente preguntarse, ¿Por qué las intendencias sur andinas continuaron sosteniendo lo restante del virreinato peruano?, y ¿Cómo estuvo configurada la intendencia de Arequipa durante esa crítica coyuntura? Es muy probable que el apoyo a la causa del rey se debiera a la implementación de las reformas borbónicas, iniciadas a fines del siglo XVIII. ${ }^{5}$ Los borbones buscaban atraer a las colonias como Arequipa a la órbita imperial. Desde esta perspectiva, los reformadores lograron éxitos significativos, entre ellos, los más importantes fueron el sistema de intendencias y las iniciativas fiscales. (Brown, 2008, p. 276).

En este sentido, resulta muy ilustrativo lo expuesto por la historiadora Teresa Cañedo-Arguelles, quien refiere que durante los años que precedieron a la ruptura con España, el virreinato peruano fue escenario de una febril actividad destinada a exaltar los valores patrióticos y la adhesión de los indios a la causa realista, que se perfilaba ya como contrapunto de la sagrada causa de la Independencia (2004). Indica que estas celebraciones estuvieron cargadas de simbolismo alrededor de la imagen del monarca:

Invención, ficción o teatro, era para los indios aquella fiesta cuyo excéntrico diseño servía para ensalzar la figura del Rey (tan desconocida como ajena) e introducirla, sin mucho éxito, en su imaginario. Solo cuando finalizó el protocolo ceremonial y comenzó a sonar la música pocihte (y con ella el baile y la embriaguez) su papel de espectadores se transformó en el de actores. Esa era su fiesta... (Cañedo-Arguelles, 2004, p.70).

Otro motivo que justificaba el apoyo realista, se debió a una participación militar previa. Esta virtud fue defendida y demostrada por sus participantes a través de documentación personal. ${ }^{6}$ El historiador Kendall Brown reflexiona al respecto e

5. En 1818, el virrey Joaquín de la Pezuela intercedió ante el rey para que la audiencia del Cuzco se trasladará a Arequipa. Tuvo como antecedentes la solicitud realizada por el diputado Mariano Rivero y Besoain y la solicitud de la propia Audiencia para su traslado a Arequipa. CDIP, Tomo XXII, volumen 2, 1972, pp.33-37.

6. De hecho, el perfil realista de los criollos, que enfrentaron a las juntas de gobierno altoperuanas y bonaerense, tiene como antecedente su participación enfrentando a la gran rebelión de Túpac Amaru II. Por su participación, los arequipeños ganaron el título de fidelísima para su ciudad y fueron denominados comúnmente restauradores del Collao. 
indica que quizá más importante que la pregunta de si la revuelta (rebelión de los pasquines) perseguía liberar a Arequipa del dominio español, es la de cómo la rebelión (de Túpac Amaru II) cambió la región en lo que restaba del período colonial (Brown, 2008, p.270). Durante 1809 y los años siguientes, tropas sur andinas consiguieron una nueva experiencia militar en el Alto Perú, la que se tradujo en que sus jurisdicciones y ciudades de origen se fueran consolidando como centros de apoyo a la causa del rey. (Chambers, 2003; Pilco, 2017) 7 .

Por lo tanto, es pertinente resaltar lo siguiente: pocos años antes de la desocupación de Lima ocurrieron dos hechos relevantes que nos ayudarán a comprender lo antes señalado. En marzo de 1817, el cabildo de Arequipa recibió un correo de Lima indicando que el teniente coronel José Manuel Goyeneche había sido nombrado Gentil hombre de Cámara con exercicio y con destino al Quarto del serenísimo Señor Ynfante Don Antonio, el cabildo acuerda agradecer esta decisión pues le fue concedida a un benemérito hijo de esa ciudad. ${ }^{8}$

De hecho, esto podría interpretarse como una muestra de los intereses arequipeños por mantenerse en la óptica peninsular. En octubre del mismo año, el cabildo recibió la noticia de que José Sebastián Goyeneche había sido premiado con la Exaltación a la Dignidad Episcopal de esta Diócesis. Por esto, se acordó comisionar festejos, iluminación de la galería del cabildo y tres noches de fuegos artificiales. ${ }^{9}$ Siguiendo las formalidades del caso, José Sebastián informó al cabildo, el 4 de junio de 1818, acerca de su próximo viaje a Lima para realizar su consagración episcopal y dejó como gobernador del obispado a Francisco Javier Echeverría y en caso de fallecer este, lo supliría Manuel Menaut Hidalgo. ${ }^{10}$

Esta noticia fue comunicada al vicario de Tacna, Juan José de la Fuente y Bustamante, quien ordenó cantar una misa te deum y circular dicha noticia en su vicaría. ${ }^{11}$ Asimismo, el cabildo y el intendente prepararon la recepción del obispo Goyeneche

7. También se debe añadir la presencia de un número importante y mayoritario de criollos en puestos clave; esto consolidó su posición a nivel político y religioso De los ocho intendentes que gobernaron Arequipa, entre interinos y electos, los cuatro últimos fueron criollos: José Gabriel Moscoso (18121814), Juan Pio Tristán Moscoso (1814-1816), José Mariano Menaut Hidalgo (1816) y Juan Bautista Lavalle y Sugasti (1816-1825). En 1817, José Sebastián de Goyeneche y Barreda fue consagrado como obispo de Arequipa. Así mismo un gran número de criollos ocuparon puestos en el cabildo, en la iglesia y fueron funcionarios en diversas subdelegaciones del virreinato peruano.

8. AMA, LAC, $\mathrm{N}^{\circ} 28,1815-1820$, sesión del 13 de marzo de 18117, f.56v.

9. AMA, LAC, $\mathrm{N}^{\circ} 28,1815-1820$, sesión del 16 de octubre de 1817, f.72r-v.

10. AMA, LAC, $\mathrm{N}^{\circ} 28,1815-1820$, sesión del 4 de junio de 1818, f.91v.

11 AAA, Correspondencia, Siglo XIX, Leg. 107, «Oficio de José Sebastián de Goyeneche y Barreda, al vicario de Tacna Juan José de la Fuente y Loayza, informándole sobre su consagración episcopal realizada en Lima, 14 agosto 1818». 
en octubre de $1818 .{ }^{12}$ Este acontecimiento brindó mayor representatividad a los criollos arequipeños. ${ }^{13}$ También se aseguraba la presencia de un hijo de la ciudad en un puesto sumamente importante.

Lo mismo sucedió en los primeros años de conflicto, cuando José Manuel Goyeneche peleó en el frente altoperuano. En esta nueva coyuntura, José Sebastián combatió y defendió su diócesis durante los últimos años del gobierno español. ${ }^{14}$ No fue hasta 1822, cuando al obispo Goyeneche se le encargaría una función más elevada. El 10 de julio de 1822, el virrey La Serna escribió lo siguiente:

Habiendo visto precisado evacuar la capital de Lima para atender a la conservación de lo restante del Reyno, y fue inevitable el que la ocupase el enemigo, y que quedase incomunicado no solo con la parte libre de su Diócesis protegida, protegida por las Armas Nacionales sino también con las demás de las Provincias Libres: a este se agregó la violenta separación de su respetable Excelentísimo e Ylustrísimo Señor arzobispo por los enemigos [...] y conforme en que el Señor Comprovincial más digno, que lo es por la mayor antigüedad de su consagración el Excelentísimo e Ylustrísimo Señor Obispo de Arequipa, exersa las prerrogativas, y funciones de Metropolitano, y el Ylustrísimo Señor Obispo de esta Diócesis del Cuzco, que resulta serle el más inmediato, las de Apostólico [...]. ${ }^{15}$

De esta manera, Arequipa, mediante su obispo, ganaba mayores prerrogativas y la ubicaba como un espacio central durante este período de tiempo. En el aspecto político, Arequipa estuvo gobernada por el criollo limeño Juan Bautista Lavalle y Zugasti, quien fue el último intendente y gobernó desde 1816 a $1825 .{ }^{16} \mathrm{Al}$ parecer, la primera comunicación oficial de Lavalle, con las autoridades arequipeñas, fue un oficio remitido al cabildo el 24 de marzo de 1816, allí informaba acerca de su designación como intendente. ${ }^{17}$ En agosto de dicho año, el regidor Juan Mariano

12 AMA, LAC No 28, 1815-1820, sesión del 9 de octubre de 1818, f.100v-101r.

13 Ernesto Rojas Ingunza refiere que la elite arequipeña, casi en bloque, había mantenido un realismo comprometido e incluso combativo desde los tiempos de Abascal y aún antes, José Sebastián se distinguiría en ella por su entrañable adhesión filial a la autoridad legítima, justa e incontrastable, de Fernando VII. (Ingunza, 2007, pp. 32-36).

14 Por su parte, Carlos Malamud señala que José Sebastián se mostró totalmente favorable a Fernando VII, tuvo una actitud conservadora ante la independencia, finalmente reconoció la independencia del Perú el 7 de febrero de 1825. Por lo que, solicitó apoyo a la población a las nuevas autoridades, y a estás, respeto a la religión católica. (Malamud, 1982, pp. 113-117).

15 AAA, Correspondencia, Siglo XIX, Leg. 72, «Oficio circular del obispo José Sebastián de Goyeneche al fray Santiago de la Cuesta, cura coadjutor de Caylloma, informándole sobre la orden del virrey acerca de sus prerrogativas y funciones de Metropolitano, 12 de agosto de 1822».

16. Lavalle fue elegido en reemplazo de Juan Pio Tristán Moscoso, quien fue designado como presidente de la Audiencia del Cuzco.

17. AMA, LAC, $\mathrm{N}^{\circ} 28,1815-1820$, sesión del 16 de mayo de 05 de 1816, f.26r. 
Goyeneche dio cuenta que él era el encargado de los preparativos para el recibimiento de Lavalle, por lo que solicitó dinero al cabildo. ${ }^{18}$

Sin embargo, recién el 11 de diciembre de 1816 se realizó su recibimiento de manos del intendente interino José Mariano Menaut Hidalgo. ${ }^{19}$ En mayo de 1818, el regidor Juan Manuel Salamanca, en representación del cabildo, señaló que se solicitaría al rey la concesión del título de Brigadier al coronel Lavalle, las razones expuestas fueron: por su esfuerzo demostrado al haber formado el resguardo de la costa, apoyo a la expedición a Chile y el refuerzo al ejército del Alto Perú, así como también la energía desplegada en su gobierno. ${ }^{20}$

A los títulos conferidos a Lavalle debemos añadir el de Segundo Comandante General del Cuerpo de Reserva acantonado en la ciudad, tenemos conocimiento de esto cuando presidía la elección del cabildo para el año de $1820 .{ }^{21}$ Un hecho trascendental durante su gobierno fue la juramentación de los Ayuntamientos Constitucionales (Sala i Vila, 2011). Los preparativos, reunión, invitaciones, recorrido y lo relacionado con ese evento se anotaron detalladamente en la sesión de cabildo del 19 de octubre, también se copiaron los actos de la ceremonia de juramentación que se llevó a cabo el 29 de dicho mes. ${ }^{22}$

Durante el gobierno de Lavalle, también se instaló la Academia Lauretana de Ciencias y Artes de Arequipa el 10 de diciembre de 1821, este acontecimiento se llevó a cabo sin la autorización correspondiente, su aprobación fue comunicada por el virrey La Serna el 13 de septiembre de $1822 .{ }^{23}$ Su instalación se realizó en momentos de profundos cambios políticos:

El nacimiento de la Academia se produce en medio de una coyuntura y de una crisis que la articula; finaliza la colonia e insurge la república a través de la lucha de la Independencia. Arequipa había participado del modo más directo en los hechos que sucesivamente la afectaban: la presencia de autoridades y tropas

18. AMA, LAC, $\mathrm{N}^{\circ} 28,1815-1820$, sesión del 01 de agosto de 1816, f.32v.

19. AMA, LAC, $\mathrm{N}^{\circ} 28,1815-1820$, sesión del 11 de diciembre de 1816, f.43v.

20. AMA, LAC, $\mathrm{N}^{\circ} 28,1815-1820$, sesión del 07 de mayo de 1818, f.88v. En mayo de 1819, se acordó que era preciso volver a informar los méritos de Lavalle; se solicitaron informes a Mariano Ricafort, o en su defecto él debía pasarlos a Su Majestad. En: AMA, LAC, N 1815-1820, sesión del 13 mayo de 05-1819, f.129r.

21. AMA, LAC, $\mathrm{N}^{\circ} 28,1815-1820$, sesión del 01 de enero de 1820, f.149r.

22. AMA, LAC, $\mathrm{N}^{\circ} 28,1815-1820$, sesión del 19 de octubre de 1820, f.171r-173v, y AMA, LAC, $\mathrm{N}^{\circ} 28$, 1815-1820, sesión del 29 de octubre de 1820, f.173r-176v. (Mazzeo, 2000, pp.61-63)

23. La historia de la Academia Lauretana de Arequipa puede ser vista en: H. Ballón, G. Galdós y E. Quiroz, Academia Lauretana de Ciencias de Arequipa. Arequipa: Colegio de Abogados de Arequipa - Script. Dicha obra tiene un Anexo, «Historia de la Academia Lauretana de Ciencias y Artes de Arequipa. Reglamento y actas de esta sociedad», pp. 253-383. Allí se refieren a sus antecedentes, instalación y funcionamiento hasta 1856. 
realistas y la de los rebeldes [...] la insistencia en designar académicos natos a los principales autoridades de Arequipa, entre ellas a las eclesiásticas, políticos y militares, revela un propósito institucional, que sería el de rodear a la naciente institución de todos los medios seguros para su funcionamiento, evitando suspicacias que pudieran provocar dificultades ulteriores. (Quiroz, 1999, pp. 236-237).

La presencia del general realista Juan Ramírez Orozco, de los patriotas José María Corbacho Abril y Manuel Amat y León en este espacio, son un indicio que no puede ayudar a discernir estas afirmaciones. Lo cierto es que, la instalación de La Academia Lauretana fue un hito fundamental porque, como se ha señalado, conjugó la presencia de eclesiásticos, políticos y militares en dicha institución. Asimismo, puede ser tomado como un instrumento de medición política, dado que su instalación se llevó a cabo en una coyuntura crítica y porque reunió a connotados patriotas y realistas en un mismo espacio.

\section{Posicionamiento militar, civil y religioso de Arequipa durante los años: 1820-1821}

Arequipa fue un punto privilegiado porque fue el nexo entre lo que restaba del virreinato peruano y la península, debido a un factor muy importante: su extensa costa. A su vez, este fue un frente de batalla enorme por donde incursionaron tropas patriotas para intentar ganarse a su población y consolidar el sistema independentista. Queda claro entonces, que en este espacio geográfico patriotas y realistas tuvieron apoyo popular en su respectivo momento. De hecho, no resulta posible medir el nivel de patriotismo o realismo en esta coyuntura. Lo cierto es que, como refiere John Frederick Wibel:

This threat increased Arequipa's military importance, because the region became the key to defense of southern Perú. By 1818 some 2600 regular royalist troops were stationed in the intendency, and Viceroy Joaquín [de] [la] Pezuela, who had succeeded Abascal in 1816, explained that Arequipa's defense was one of his first priorities after that of the viceregal capital. (Wibel, 1975, p.269).

La guerra había llegado a un punto sin retorno, pues se abrieron dos frentes de batalla. San Martín dirigió a los insurgentes desde el Río de la Plata a través de los Andes hasta Chile, mientras que, en el norte, Simón Bolívar comandaba las fuerzas centradas en Nueva Granada. En la década de 1820, ambos movimientos convergieron en el Perú (Walker, 1999, p. 113). Como resultado, Perú pasó a tener un gobierno patriota en Lima, encabezado por San Martín; y un gobierno realista en el Cuzco, liderado por el virrey La Serna, el cual controlaba la mitad del virreinato, y, sobre todo, el territorio de la sierra y sus recursos naturales (O'Phelan, 2013, p. 197). 
Tal como señala la historiadora Cristina Mazzeo, la situación de Chile determinó que el ejército realista buscará recomponerse y afianzarse en la costa sur del Perú, ya que este punto resultaba el más vulnerable en caso de una invasión independentista. Asimismo, las intendencias de Arequipa, Cuzco y Puno debían proveer lo necesario para la organización del ejército de reserva (Mazzeo, 2000, pp. 13-14). Por ello, que el 2 de julio de 1818 se hicieron los preparativos para recibir al comandante general del Exército de Reserva Mariano Ricafort y a sus respectivos oficiales. ${ }^{24}$

Desde entonces, la búsqueda de recursos será una constante; el intendente Lavalle informó al cabildo acerca de un Plan Caudal para la manutención del ejército de reserva formado por Ricafort, el monto estimado fue de 40.000 pesos para:

[...] solo sueldos de tropa y Señores oficiales, sin inclusión de los gastos de monturas, fornituras, y otros precisos útiles de guerra que diariamente ocurren [...] para subvenir a las necesidades del día por la urgencia de mantener unas tropas que pueden contener las imbaciones del Enemigo de que resulta nuestra propia utilidad y conservación de propiedad, y lo que es más la justa defensa de los Derechos del Rey [...]. 25

La falta de fondos obligó al cabildo a formar una razón de sujetos pudientes para que haga un empréstito y de esta manera cubrir el monto solicitado. La reunión se llevaría a cabo el 22 de agosto de dicho año. Es muy probable que este tipo de solicitudes monetarias haya sido recurrente y pudo llevar a la organización de una instancia propia, encargada de hacer los arreglos económicos correspondientes. En 1820, el obispo Goyeneche le escribió al vicario de Arica Pedro José Vélez, dice:

En Junta de Corporaciones del día 21 de Abril último, se ha determinado continué la exacción del cinco por ciento de rentas eclesiásticas por otro año, o el menos tiempo que duren las necesidades del Real Erario para sostener el Exército de Recerva que defiende no solo esta Capital sino también las Provincias circunvecinas de los insultos que podrían hacernos los enemigos de nuestro sosiego $[\ldots] .^{26}$

Le pide que circule esa comunicación en su vicaría, recolecte las cantidades a razón del año anterior y las remita a su secretaria de Cámara. Esta circular llegó

24. AMA, LAC $\mathrm{N}^{\circ} 28,1815-1820$, sesión del 2 de julio de 1818, f. 93v. El cuerpo de reserva en Arequipa estaba conformado de 2000 plazas y 1000 en Arica, estaban bajo las órdenes de Mariano Ricafort, este número permitía movilidad en caso que los enemigos atacaran Lima o el sur de Arica. En: Distribución del ejército a lo largo de la costa del Perú en ocasión de los sucesos de Chile (Mazzeo, 2000, pp.61-63.

25. AMA, LAC $\mathrm{N}^{\circ}$ 28, 1815-1820, sesión del 20 de agosto de 1818, f.97v-98r. Riveros, 2017.

26. AAA, Correspondencia, Siglo XIX, Leg. 48, «Oficio circular del obispo José Sebastián Goyeneche al vicario de Arica Pedro José Vélez, informándole lo determinado por la Junta de Corporaciones, 30 de junio de 1820». El subrayado es nuestro. 
a Arica el 16 de agosto, a Codpa el 23 y a Parinacota de Belén el 9 de septiembre. En total, se reunieron 173 pesos 4 reales. Estos fueron remitidos a Arequipa el 23 de septiembre de $1820 .{ }^{27}$ Coincide plenamente con lo que refiere Cristina Mazzeo; Arequipa no solo debía proveer hombres sino también recursos económicos, vituallas y prácticamente todo lo necesario para el ejército de Reserva y los otros que iban llegando, organizarlos en verdaderos cuerpos de línea y luego redistribuirlo según lo solicitasen (Mazzeo, 2000, p. 17).

En mayo de 1819, el cabildo acordó informar al rey los méritos del brigadier Ricafort, por su incansable labor al mando del ejército de Reserva. Una semana después, el intendente solicitó lo mismo para el coronel mayor del cuerpo de reserva, José Carratalá, en ambos casos no se hace mención de su posible salida o remoción ${ }^{28}$. Ese mismo año, hizo su paso por Arequipa Juan Ramírez Orozco, General en Gefe del Exercito Real de Operaciones en el Alto Perú, quien se encontraban de tránsito hacia tierras altoperuanas. ${ }^{29}$

Ramírez había ocupado la presidencia de Quito hasta noviembre de 1819. En 1820 lo encontramos en la intendencia de Puno; sin embargo, fue destituido por el virrey La Serna para ser reemplazado por José de Canterac (Mazzeo, 2009, pp. 121-126). De esta forma, Juan Ramírez pasó nuevamente por Arequipa camino hacia la costa por donde pensaba retirarse a la península; sin embargo, su viaje fue interrumpido y permaneció en dicha ciudad como la autoridad de mayor rango; debemos resaltar que su presencia fue determinante y notable.

Tal como indica Jaime Rosemblitt, si bien hay elementos que la señalan como una campaña exitosa (la de los puertos intermedios), la ventaja estratégica alcanzada por el Ejército Libertador se diluyó al llegar noticias del armisticio que el general José de San Martin y el virrey José de La Serna habían firmado en Punchauca el 2 de junio de 1821. Pues, mientras el general Juan Ramírez aprovechó el tiempo para formar en Arequipa un nuevo ejército de dos mil hombres, los patriotas no recibieron refuerzos y se vieron imposibilitados de entrar en combate por los estragos que causaban las enfermedades, es así que se retiraron el mes de julio de 1821. (Rosemblitt, 2013, pp. 189-190).

27. Es muy probable que la Junta de Corporaciones haya involucrado a los cabildos de Arequipa, cabildos eclesiásticos, a la Aduana, a las Cajas Reales entre otras instituciones. De no ser así, resulta poco creíble el sostenimiento de un ejército que necesitaba 40000 pesos para su subsistencia. El caso que se presenta, corresponde a la Vicaría de Arica, nótese el tiempo de envió, recepción y retorno de dicha circular.

28. AMA, LAC $\mathrm{N}^{\circ} 28,1815-1820$, sesión del 22 de mayo de 1819, f. 130r, y AMA, LAC Nº 28, 1815-1820, sesión del 27 de mayo de 1819, f. 130v. Respectivamente.

29. AMA, LAC No 28, 1815-1820, sesión del 4 de diciembre de 1819, f. 143r. 


\section{Incursión patriota a los puertos intermedios: 1821}

La convergencia de los ejércitos patriotas va a centrar su atención en los puertos, por lo que la región Tacno-ariqueña fue uno de sus objetivos. Es así que San Martin:

[...] comisionó al almirante Thomas Cochrane para zarpar con la escuadra a reconocer la costa hacia el sur $y$, donde fuese posible, desembarcar al destacamento de seiscientos ochenta hombres, encabezado por el teniente William Miller, capturar algún punto con valor estrategia. Esto para atraer a las fuerzas realistas del sur peruano y Alto Perú, e impedir su reunión con las que estaban en Lima y en la sierra. (Rosemblitt, 2013, p. 187).

Luego de que las tropas patriotas estuvieron en Pisco, se embarcaron en el navío San Martín y partieron el 22 de abril hacia el sur. A comienzo de mayo de 1821, llegaron a Arica, anclaron fuera de tiro de cañón e intimaron a las autoridades ariqueñas. Miller informa que Arica tenía una guarnición de entre 300 y 400 hombres, y el punto de desembarco estaba defendido por una batería de seis piezas. Sumado a la bravura del mar, desembarcar parecía impracticable. Por este motivo, se realizaron algunas maniobras para desembarcar, pero fracasaron. Se optó por otra acción, un grupo de soldados fueron traslados hasta al Morro de Sama, posteriormente llegaron al valle del mismo nombre.

Luego, esa división se dirigió a Tacna, allí Miller fue recibido con el mayor entusiasmo por el clero, el ayuntamiento y sus habitantes, que salieron a recibirle fuera de la villa (Miller, 1975[1829], p. 220).$^{30}$ Esto ocurría mientras que otro grupo avanzaba del morro de Sama hacia Arica. Este destacamento estuvo dirigido por el mayor Soler, las noticias de esta avanzada provocaron el desbando de la guarnición de Arica. Soler persiguió y alcanzó a estos soldados por el camino que se dirigía al valle de Azapa e hizo cien prisioneros. Ellos fueron admitidos en las filas de los patriotas, una vez reunidos en Tacna.

Al poco tiempo, Bernardo Landa Vizcarra se presentó ante Miller para ofrecer su conocimiento sobre los puertos intermedios. ${ }^{31}$ Durante estas operaciones, el general Ramírez dirigió tres destacamentos, el primero de 180 hombres de Arequipa a Moquegua, allí se le unieron 100 hombres; uno desde Puno y otro desde La Paz. Estos debían juntarse en Tacna y luego echar al mar a los insurgentes. (Miller, 1975[1829], p. 221). ${ }^{32}$ Cuando Miller supo esto, decidió atacar dichos

30. Este párrafo nos ofrece una impresión interesante, y es un síntoma recurrente durante las guerras de independencia. Es decir, la población recibía al bando vencedor, en este caso al patriota.

31. Ver: Glave, 2015; Valcárcel, 2015 y Wibel, 1975, pp.290-291.

32. De hecho, el general Ramírez estaba al tanto de estas acciones. En dos oficios enviados al juez subdelegado de Tarapacá Felipe Pelando le informa acerca de los movimientos de José Santos de la Hera, para operar contra los insurgentes, y le sugiere que le preste la ayuda adecuada. Ambos fueron 
destacamentos por separado. Primero iría por el del coronel José Santos de la Hera, por lo que juntó a sus fuerzas en Tacna, estas constaban de 350 infantes, 70 de caballería y 60 paisanos voluntarios.

El movimiento de ambos bandos se concentró en Mirave el 22 de mayo, luego de un breve combate, los realistas fueron desalojados de sus posiciones. Sin embargo, el refuerzo de Puno y La Paz se presentó a su vista, por ello, los patriotas se prepararon para un nuevo embate, lo que no ocurrió. Ese mismo día, Miller persiguió a los soldados de la división de la Hera que habían escapado hacia Moquegua (Miller, 1975[1829], pp. 226-227).

Las tropas de Miller llegaron a Locumba, donde fueron recibidas por sus habitantes. Bernardo Landa se adelantó a esta marcha, su intención era cortar la comunicación de Moquegua por su salida o lado oriental. ${ }^{33}$ Los patriotas llegaron el 24 de mayo, los fugitivos realistas llegaron allí con unas horas de adelanto, mientras que el coronel La Hera continuó rumbo a Puno. Los soldados realistas que se quedaron en Moquegua fueron sorprendidos por las fuerzas de Miller, ellos se retiraron de la ciudad en orden, pero fueron alcanzados y derrotados por la caballería patriota al mando del mayor Soler. Miller informó que el subdelegado de Moquegua, Mariano Portocarrero, pasó a formar parte de sus filas. ${ }^{34}$

El 25 de mayo, Miller supo del movimiento de las tropas que habían estado a la retaguardia de la batalla de Mirave, luego de perseguirlas fueron desbaratadas. Asimismo, se realizaron una serie de movimientos en la región para reconocer la geografía Moqueguana ${ }^{35}$. Por lo que decidió movilizarse el 4 de junio, ese mismo

escritos en el Cuartel general de Arequipa y tienen como fecha de emisión el 6 y 7 de mayo de 1821. Apéndice, Oficios del general Ramírez que hacen relación a las medidas que adoptó para contener los progresos de Miller a su desembarco en Arica. (Miller, 1975[1829], pp. 323-324).

33. De esta manera cortaba el camino de comunicación de Moquegua con las ciudades de Puno y Tacna. Por su parte, el intendente Lavalle escribió al ayuntamiento constitucional de Carumas. Le informa que tiene noticias sobre la ocupación de Moquegua, ordena que hasta que no se restablezca el orden se debe cortar toda comunicación con dicha villa y que debían avisar mediante un parte los movimientos del enemigo. Fechada el 26 de mayo de 1821. Apéndice, Oficio del Doctor Don Juan Bautista de Lavalle con objeto de privar de subsistencias a los patriotas. (Miller, 1975[1829], pp. 324-325).

34. Miller refiere que fue recibido en Moquegua con las mayores muestras de alegría, y como prueba de su sincera adhesión a la causa de la independencia, voluntaria y cuidadosamente, facilitaron todos los medios para que su división recobre sus fuerzas. (Miller, 1975[1829], p.228). También refiere que el espíritu patriótico se había despertado y se difundió con entusiasmo y rapidez.

35. El coronel Miller refiere que cuando se retiró de Moquegua a Tacna, envió a un teniente de apellido La Tapia, con un trompeta, unos soldados y una partida de montoneras con órdenes de aproximarse a Arequipa. Este militar se dirigió a Arequipa como parlamentario y fue conducido hasta Ramírez. Allí conversaron acerca del armisticio que firmaron sus líderes, sin embargo, las fechas no coincidían en sus diálogos. Aun así, fue recibido y se le prestaron las atenciones debidas. Este acontecimiento produjo sensación general entre los patriotas de Arequipa. Por lo que, Ramírez lo despidió rápidamente. (Miller, 1975[1829], p. 235). 
día supo de los movimientos de La Hera, quien se aproximaba desde Santiago de Machaca, con la intención de cortarle el camino hacia la costa. Sus próximos movimientos lo llevaron a Ilo y Tacna, el 12 de junio recibió una correspondencia interceptada de Ramírez al coronel La Hera, allí anunciaban el armisticio de Punchauca. También indica que las fuerzas La Hera regresaron a Santiago de Machaca, pues suponían que las tropas patriotas eran superiores. (Miller, 1975[1829], pp. 230-231).

La posición de Miller era favorable, contaba con varios puntos de avanzada en los alrededores de Moquegua y Tacna, sus fuerzas aumentaron a un número de 900 efectivos, había formado varias partidas de montoneras y había abierto comunicación con el coronel Lanza, jefe de una guerrilla en el Alto Perú. ${ }^{36}$ Por lo desprendido de la lectura, se infiere que tanto Cochrane como Miller estaban dispuestos a una empresa mayor, más allá de importunar a las fuerzas realistas en los puertos intermedios. Cochrane había solicitado refuerzos de tropas y armamentos para Miller, quien sin ser auxiliado a tiempo no pudo aprovechar esa oportunidad, que:

Fácilmente puede concebirse con que pesar tendría que abandonar las ventajas obtenidas a tanta costa, y más cuando el halagüeño prospecto de las cosas, no solo le ofrecían la posibilidad de mantener el terreno que ocupaban sino tomar posesión de Arequipa, cuyos habitantes estaban decididamente dispuestos a su favor. En este rica y populosa ciudad habría aumentado y organizado sus fuerzas, se habría dirigido hacia el Cuzco, y por este medio habría puesto al ejército realista a las órdenes del virrey en Huancayo y Jauja en una situación muy crítica. (Miller, 1975[1829], p. 235).

Este intermedio fue aprovechado por Ramírez, quien logró aumentar sus fuerzas en 2000 hombres; asimismo, poco antes de expirar el armisticio, el coronel La Hera marchó con 1000 hombres desde Santiago de Machaca y ocupó Moquegua. El 15 de julio anunció oficialmente la renovación de las hostilidades. ${ }^{37}$ Miller llamó a

36. A su vez, el coronel La Hera, comandante general de la división expedicionaria de la costa de Tacna, mediante una orden circular instaba a las tropas del Rey que se hallaban en los partidos de Tacna y Moquegua, a replegarse a marchas forzadas para unirse a él y al batallón Gerona que componían sus fuerzas. Para lo cual debían dirigirse a Palca, Guailillas o puntos inmediatos que van de Oruro a Tacna, también debían informarle sobre sus avances. Fechada el 30 de mayo. Apéndice, Orden circular de La Hera para que se le incorporen todas las tropas y destacamentos. (Miller, 1975[1829], pp. 328-329).

37. La Hera informa que fue el excelentísimo señor general en jefe del ejército del Perú La Serna fue quien dio la autorización de ocupar la villa de Moquegua. Esto no debe considerarse un acto hostil. Recuerda que las fuerzas de Miller ocuparon Tacna, que una partida se llevó caballos de Caraquen y que se embarcaron trigos en Mollendo. Así mismo, hace responsable al señor comandante general de las fuerzas de Chile Miller, situadas en la costa del Sur, responsable de cualquier ulterior suceso. Miller responde que recibió la noticia del armisticio tratado en Punchauca días después de haber ocupado Tacna y que la toma de caballos está explicada satisfactoriamente por un oficio adjunto, y que su conducta está regulada por los principios que marca el deber. Fechadas respectivamente el 5 
sus destacamentos, entre el 19 y 20 de julio las tropas patriotas se movilizaron de Tacna a Arica, allí los esperaban:

El venerable Don Agustín Zapata, natural de Moquegua; las respetadísimas familias de Landa y Lazos, la de Potrillo, y otras muchas personas [...] prefiriendo emigrar sujetarse nuevamente al yugo español. No pocos más querían seguir la suerte de los patriotas [...]. Entre ellos estaban Don Enrique Solar y D[on]. $\mathrm{N}$ [icolas]. Boteler ${ }^{38}$ que ambos se habían comprometido, admitiendo destino al servicio de los patriotas. (Miller, 1975[1829], p.237).

El coronel La Hera le seguía los pasos, pero se detuvo en Tacna. Esto dio tiempo a los patriotas para retirarse por mar. Su retiro dependía de cuatro buques mercantes, anclados en la bahía de Arica. Miller refiere en sus memorias que el gobernador de Arica había enviado tres soldados a tomar una goleta de Estados Unidos. Si bien la situación se complicó:

Es de advertir que la gente de mar que navegaba en el Pacifico, fuesen ingleses o de la América del Norte, sirvieran en buques de guerra o mercantes, habían manifestado siempre el mayor interés en los triunfos de Miller, y este interés, que les había sabido inspirar por su buen comporte, produjo un efecto de la mayor importancia en esta ocasión. [...] declarando con resolución, «Que no abandonarían a un paisano suyo que se hallaba en tan inminente peligro». (Miller, 1975[1829], p. 238).

Miller indica que, durante su desembarco, en mayo, los habitantes de Arica eran realistas decididos. Esto debido al saqueo de la ciudad por los marineros del navío San Martin, situación que se revirtió por el cambio de conducta de oficiales y soldados patriotas. Al momento de embarcarse recibieron ayuda de la población, acción que se retrasó porque el número de emigrados que decidieron seguir la causa patriota sumó 100 personas más. Finalmente, levaron anclas el 22 de julio.

De esta manera, llegó a su fin esta incursión a los puertos intermedios. Esta breve irrupción patriota duró tres meses y permitió a ambos bandos probar sus fuerzas.

y 9 de julio. Apéndice, Oficio del coronel La Hera en que con razones especiosas y palabras huecas pretende disculpar su infracción al armisticio de Punchauca, y contestación de Miller. (Miller, 1975[1829], pp.331-332).

38. Rosemblitt nos informa que Nicolás Buteler fue el único de los procesados por tomar parte en la revuelta de (Tacna) de 1813 con intereses mercantiles de cierta importancia, y que recién comenzaba su carrera empresaria. Era miembro de una familia irlandesa radicada, en 1740 en Córdoba, virreinato del (Río de la) Plata, la Caja Real era entonces su principal cliente, luego de la suscripción de dos convenios para hacerse cargo del sostenimiento de las guarniciones militares de Arica e Ilo. Aunque formó familia y radicó en Tacna, y entre 1820 y 1830 llegó a ser uno de los principales mercaderes criollos. Es difícil suponer que su participación en la segunda insurrección tacneña no estuviera animada por otras cosas que sus convicciones políticas, sus cálculos lo condujeron a ponerse al lado de la corona. (Rosemblitt, 2013, pp. 186-187). 
Los patriotas comprobaron que efectuar una incursión armada a los puertos intermedios era posible, allí contaron con apoyo de la población y de algunas de sus autoridades. La respuesta de los realistas, podría considerarse parsimoniosa, pero debemos recordar que Juan Ramírez estaba en Arequipa. Él era el militar de mayor rango, su experiencia pudo tranquilizar y animar a los realistas en esta crítica coyuntura. Lo cierto es que, los arequipeños pudieron superar la incursión patriota, y los militares presentes en la intendencia procuraron recuperarse y tomar esta experiencia previa para enfrentar retos futuros.

\section{Reflexiones finales}

Las guerras de la independencia fueron procesos complejos. Los primeros años de conflicto fueron favorables para las tropas realistas peruanas, pero a medida que el conflicto arreciaba, comenzaron a notarse una serie de problemas que afectaron a las fuerzas peruanas. Un problema resaltante era la economía que fue seriamente afectada a medida que el conflicto transcurría y llegó a un nivel crítico con la pérdida de la capitanía general de Chile.

La incursión patriota a Lima, por las fuerzas de San Martín, provocó la desocupación de la capital y el traslado del centro del gobierno a la ciudad del Cuzco. Por esto, Huamanga, Huancavelica, Arequipa, Cuzco, Puno y las intendencias altoperuanas se convirtieron en el soporte del restante virreinato peruano. En este contexto, la intendencia del Cuzco fue el epicentro político, mientras que la intendencia de Arequipa fue el principal centro religioso y se convirtió en el nexo entre el virreinato del Perú y la península.

Esta situación demuestra que los regionalismos eran fuertes y las intendencias sur andinas se encontraban en condiciones de sostener, al menos temporalmente, a los ejércitos reconcentrados y al aparato burocrático aún existente en sus territorios. Es muy probable que este apoyo a las fuerzas realistas, se deba en parte al éxito de las reformas borbónicas, iniciadas a fines del siglo XVIII, a la experiencia militar previa, defendiendo los derechos reales en 1780-1783 y nuevamente a partir de 1809, y a la posición favorable de un número importante de criollos en puestos claves de gobierno.

Esta incursión a los puertos intermedios mostró que los patriotas contaron con apoyo popular y de algunas autoridades locales. Su campaña victoriosa pudo ser tomada como antecedente para realizar expediciones más numerosas y mejor preparadas. No obstante, esta experiencia también fue provechosa para los realistas que vencieron a los patriotas en Moquegua y Torata en 1823. La resistencia en el sur andino continuó hasta 1825, y solo tras las derrotas de las tropas realistas en Junín y Ayacucho en 1824, los esfuerzos por sostener el régimen español en Hispanoamérica se diluyeron gradualmente. 


\section{Referencias bibliográficas}

\section{Fuentes primarias}

Archivo Arzobispal de Arequipa (AAA).

Archivo Municipal de Arequipa (AMA).

Colección Documental de la Independencia del Perú (CDIP).

\section{Fuentes secundarias}

Anna, T. (2003). La caída del gobierno español en el Perú: el dilema de la independencia. Lima: IEP.

Alvarado, P. (2018). Los virreyes Abascal y Pezuela frente a Chile: Políticas contrarrevolucionarias del virreinato del Perú, 1810-1818. En: M. Chust y C. Rosas, El Perú en revolución. Independencia y guerra: un proceso, 1780-1826. UJI-FEPUCP-El Colegio de Michoacán A.C., pp. 249-264.

Barriga, V. M. (1953). Poesías populares con temas históricos. En: Fénix, Revista de la Biblioteca Nacional del Perú, número 9, pp. 413-423.

Brown, K. (2008). Borbones y aguardiente. La reforma imperial en el sur peruano: Arequipa en vísperas de la Independencia. Lima: BCRP-IEP.

Buller, C. (2011). Vinos, aguardiente y mercado. Auge y declive de la economía del vino en los valles de Arequipa (1770-1853). Lima: Quellca.

Calderón, F. (2018). Los últimos años del cabildo colonial de Arequipa, 1780-1821. En: M- Chust y C. Rosas, El Perú en revolución. Independencia y guerra: un proceso, 17801826. UJI-FEPUCP-El Colegio de Michoacán A.C., pp. 75-95.

Cañedo-Arguelles, T. (2004). Al sur del margen. Avatares y límites de una región postergada Moquegua (Perú). Madrid. IEP-CSIC.

Chambers, S. C. (2003). De súbditos a ciudadanos: honor, género y política en Arequipa, 1780-1854. Lima: PUCP-UP-IEP.

Condori, V. (2010). Sociedad, identidad y regionalismo en Arequipa, 1780-1830. En: Historia, UNSA, número 9, pp. 47-71.

Condori, V. (2011). Guerra y economía en Arequipa: las actividades del español Lucas de la Cotera en una coyuntura de crisis, 1821-1824. En: Revista de Indias, volumen LXXI, número 253, pp. 827-858.

Cayo, P. (1975[1829]). Memorias del General Guillermo Miller, Tomo I. Estudio preliminar de [...]. Lima: Editorial Arica.

Davio, M. (2019). La lucha por la patria atraviesa fronteras: pasquines sediciosos y difusión de ideas revolucionarias en Cerro de Pasco, Perú (1812). En: Revista Tempo, volumen, 25, n.1, Jan/Abr., 2019, pp. 72-82. 
Glave, L. M. (2015). Redes revolucionarias en 1814 de La Paz a Moquegua: Tras la huella del Dr. José Astete. En: Historia, Año 1, Número 2, Julio-diciembre, pp. 37-67

Klein, H. (1994). Fiscalidad real y gastos de gobierno. El virreinato del Perú. 1680-1809. Documento de trabajo $\mathrm{N}^{\circ}$ 66. Lima: Instituto de Estudios Peruanos.

Mazzeo, C. A. (2000). Cuadernos de investigación. Las vicisitudes de la guerra de la independencia del Perú, 1817-1824. Lima: IRA - PUCP.

Mazzeo, C. A. (2009). Los nudos de la desunión: conflictos y divergencias en la dirigencia del ejército realista durante la emancipación del Perú, 1810-1824. En: Revista de Indias, volumen LXIX, número 247, pp. 105-136.

Malamud, C. (1982). La consolidación de una familia de la oligarquía arequipeña: Los Goyeneche. En: Quinto Centenario, Madrid, número 4, pp. 49-135.

O’Phelan, S. (2009). El proceso de independencia en el Perú. En: I. Frasquet y Andréa Sleiman. De las Independencias Iberoamericanas a los estados nacionales (1810-1850). 200 años de historia. Vervuert, AHILA-IBEROAMERICANA, pp. 109-129.

O’Phelan, S. (2013). Más realistas que el Rey. Las élites del sur andino frente a la independencia del Perú. En: J. Rosemblitt Las revoluciones americanas y la formación de los Estados Nacionales. Santiago: DIBAM-CIDBA.

O’Phelan, S. (2019). El norte patriota y el sur realista. La división territorial del Perú en el contexto de la Independencia (1820-1824). En: S. O'Phelan y A. C. Ibarra. Territorialidad y poder regional de las Intendencias en las Independencias. De México y Perú. Lima: Fondo Editorial del Congreso de la República, pp. 391-431.

Quiroz, E. (1999) Significado Histórico de la Academia Lauretana de Ciencias y Artes de Arequipa. En: H. Ballón, G. Galdós y E. Quiroz, Academia Lauretana de Ciencias y Artes de Arequipa. Arequipa: Colegio de Abogados de Arequipa - Script.

Riveros, G. (2017). El cabildo de Arequipa en una coyuntura de crisis, 1809-1824. En: C. Méndez y J. C. Estenssoro. Narra la independencia desde tu pueblo 1. Huacho, Arequipa, Tarapacá. Lima: IFEA-IEP.

Rosemblitt, J. (2013). Centralidad geográfica, marginalidad política: La región de TacnaArica y su comercio, 1788-1841. Santiago: DIBAM-CIDBA.

Sala i Vila, N. (2011). El Trienio Liberal en el virreinato peruano: los ayuntamientos constitucionales de Arequipa, Cusco y Huamanga, 1820-1824. En: Revista de Indias, volumen LXXI, número 253, pp. 693-728.

Suyo, H. (2020). Conspiraciones, sediciones y revolución en la intendencia de Arequipa: 1809-1815. (Tesis de maestría). Pontifica Universidad Catolica del Perú, Lima.

Valcarcel, G. (2015). Moquegua: Los Landa y su lucha por la independencia. En: Historia, Año 1, número 1, enero-junio, pp. 85-116.

Walker, C. (1999). De Túpac Amaru a Gamarra. Cusco y la formación del Perú Republicano, 1780-1840. Cuzco: CBC. 
Wibel, J. F. (1975). The evolution of a regional community within Spanish Empire and Peruvian Nation: Arequipa, 1780-1845. A dissertation submitted to the Department of History and the committee on graduate studies of Stanford University. In partial fulfilment of the requirements for the degree of Doctor of Philosophy.

Zegarra, G. (1973). Arequipa, en el paso de la colonia a la república. Visita de Bolívar. Arequipa: Cuzzi y Cia. S.A. Impresores-Editores. 
